\title{
Percutaneous edge-to-edge repair in high-risk and elderly patients with degenerative mitral regurgitation: Midterm outcomes in a single-center experience
}

\author{
Maurizio Taramasso, MD, ${ }^{\mathrm{a}}$ Francesco Maisano, MD, ${ }^{\mathrm{b}}$ Paolo Denti, MD, ${ }^{\mathrm{a}}$ Azeem Latib, MD, \\ Giovanni La Canna, MD, ${ }^{a}$ Antonio Colombo, MD, ${ }^{\mathrm{c}}$ and Ottavio Alfieri, $\mathrm{MD}^{\mathrm{a}}$
}

Objective: The study objective was to report the midterm outcomes of MitraClip implantation in inoperable or high-risk surgical candidates with degenerative mitral regurgitation.

\begin{abstract}
Methods: From October 2008, data of all high-risk or elderly patients with severe degenerative mitral regurgitation who underwent MitraClip implantation were prospectively collected.

Results: Forty-eight high-risk consecutive patients with severe degenerative mitral regurgitation underwent MitraClip implantation (mean age, $78.5 \pm 10.8$ years; $56.6 \%$ of the patients were aged $\geq 80$ years). Mean Society of Thoracic Surgeons score was $12 \% \pm 10 \%$, and $71 \%$ were in New York Heart Association class III or IV. Mean left ventricular ejection fraction was $57 \% \pm 11 \%$. The device was successfully implanted in 47 of 48 patients $(98 \%)$. In-hospital mortality was $2 \%$. The median intensive care unit stay was 22 hours; patients were discharged from the hospital in an average of $4.5 \pm 2.4$ days. Predischarge echocardiography showed a mitral regurgitation reduction to grade $2+$ or less in 43 of 47 patients $(91.5 \%)$. Actuarial survival was $89 \% \pm 5.2 \%$ and $70.2 \% \pm 9 \%$ at 1 and 2 years, respectively $(82 \% \pm 9 \%$ in patients aged $<80$ years and $95 \% \pm 4.4 \%$ in patients aged $\geq 80$ years at 1 year; $P=.9$ ). Freedom from mitral regurgitation $3+$ or greater was $80 \% \pm 7 \%$ at 1 year and $76.6 \% \pm 7 \%$ at 2 years. At 1 year, $93 \%$ of survivors were in New York Heart Association class I or II $(100 \%$ of patients aged $<80$ years and $88 \%$ of patients aged $\geq 80$ years; $P=.4)$. Significant quality of life improvements were documented. A significant improvement in 6-minute walk test performance was observed.
\end{abstract}

Conclusions: MitraClip therapy is a valuable alternative to surgery in high-risk and elderly patients with degenerative mitral regurgitation. Clinical benefits also are obtained in octogenarians. (J Thorac Cardiovasc Surg 2014;148:2743-50)

See related commentary on pages $2750-1$.

Surgical repair represents the optimal treatment for severe degenerative mitral regurgitation (DMR) because of its well-documented advantages over valve replacement in terms of perioperative mortality, preservation of postoperative left ventricular function, and long-term survival. ${ }^{1,2}$ Indeed, if performed before the onset of limiting symptoms or the development of left ventricular dysfunction, mitral valve (MV) repair is able to restore

\footnotetext{
From the Cardiac Surgery Department, ${ }^{a}$ San Raffaele University Hospital, Milan, Italy; Division of Cardiovascular Surgery, ${ }^{\mathrm{b}}$ University Hospital of Zurich, Zurich, Switzerland; and Interventional Cardiology Unit, ${ }^{c}$ San Raffaele University Hospital, Milan, Italy.

Disclosures: Dr Maisano is a consultant for Abbott Vascular. All other authors have nothing to disclose with regard to commercial support.

Drs M.T. and F.M. contributed equally to this work and are joint first authors.

Received for publication Jan 3, 2014; revisions received March 8, 2014; accepted for publication March 21, 2014.; available ahead of print April 24, 2014.

Address for reprints: Maurizio Taramasso, MD, Cardiac Surgery Department, San Raffaele University Hospital, via Olgettina, 58, Milan, Italy (E-mail: taramasso. maurizio@hsr.it).

$0022-5223 / \$ 36.00$

Copyright (C) 2014 by The American Association for Thoracic Surgery

http://dx.doi.org/10.1016/j.jtcvs.2014.03.036
}

normal life expectancy and quality of life. ${ }^{3}$ Currently, more than $90 \%$ of degenerative lesions can be repaired successfully in high-volume centers, with low morbidity and fast recovery. ${ }^{4-6}$ In view of these results, elective MV repair may be indicated even in asymptomatic patients with severe DMR.

However, in real-world clinical practice, a large number of patients with severe mitral regurgitation (MR) are denied surgery: The Euro Heart Survey conducted by the European Society of Cardiology showed that up to $50 \%$ of the patients with severe MR currently are denied surgical treatment because they are thought to be at too high risk for surgery because of advanced age or comorbidities. ${ }^{8}$ Moreover, the prevalence of DMR increases in elderly persons, ${ }^{9}$ and advanced age is one of the main risk factors of mortality and major morbidity after cardiac surgery. ${ }^{10}$ Therefore, over the past years, new transcatheter techniques have been developed to treat MR with less-invasive approaches. Although less effective in reducing MR compared with surgical repair, ${ }^{11,12}$ MitraClip therapy (Abbott Vascular Inc, Menlo Park, Calif) has been shown to improve functional and clinical outcome in inoperable or high-risk patients. ${ }^{13-18}$ Few data are available today on the midterm clinical outcomes of high-risk patients with DMR after MitraClip implantation. 


\section{Abbreviations and Acronyms \\ ACCESS-EU $=$ ACCESS-EUROPE \\ DMR $=$ degenerative mitral regurgitation \\ euroSCORE $=$ European System for Cardiac \\ Operative Risk Evaluation \\ EVEREST = Efficacy of Vasopressin \\ Antagonism in Heart Failure \\ Outcome Study with Tolvaptan \\ IQR = interquartile range \\ MLHFQ = Minnesota Living with Heart \\ Failure Questionnaire \\ MR $=$ mitral regurgitation \\ $\mathrm{MV} \quad=$ mitral valve \\ NYHA $=$ New York Heart Association \\ 6MWT $=6$-minute walk test \\ SF-36 $=36$-Item Short-Form Health Survey \\ STS $\quad=$ Society of Thoracic Surgeons}

The aim of this study is to report the midterm clinical and echocardiographic results of MitraClip therapy to treat symptomatic high-risk or elderly patients with severe DMR in a single high-volume center experience to validate the use of MitraClip treatment in this specific setting.

\section{METHODS}

We retrospectively analyzed the clinical and echocardiographic data of a cohort of consecutive patients who underwent MitraClip therapy between October 2008 and July 2013 for severe or moderately severe symptomatic DMR. All patients underwent preoperative coronary angiography and transesophageal Doppler echocardiography. Clinical, Doppler echocardiographic, operative, and outcome data were prospectively collected in a dedicated database. The study protocol was performed in accordance with the institutional ethics committee, and all patients gave written informed consent for the procedures and data collection.

\section{Description of the Procedure}

The procedure was performed under general anesthesia in a hybrid operating room, under transesophageal Doppler echocardiography and fluoroscopic guidance. Transseptal puncture was performed using a Brockenbrough needle (Medtronic Inc, Minneapolis, Minn) through peripheral venous access at the right groin. Live real-time 3-dimensional echocardiography was used to improve the conduct of the implantation. A steerable guide catheter was advanced in the left atrium through the transseptal puncture. The delivery system was inserted, and the MitraClip device was implanted in correspondence with the origin of the regurgitation jet, perpendicularly to the coaptation line. If the effect of the implant was satisfactory, the clip was deployed. When necessary, more than 1 clip was implanted. The comprehensive description of the procedure has been reported by Maisano and colleagues. ${ }^{19}$

\section{Patient Selection}

Patients were selected if they met basic criteria for intervention from the European Society of Cardiology Task Force recommendation on the management of valvular heart disease. ${ }^{7}$ Indication for MitraClip therapy was given according to local institutional practice in consideration of current CE mark-approved labeling. Eligible patients included those with symptomatic moderate-to-severe (3+) or severe (4+) MR. Transthoracic and transesophageal echocardiograms studies were evaluated at baseline to assess patient eligibility.

All patients underwent a multimodality decision-making process by a dedicated multidisciplinary Heart Team, including evaluation of surgical risk by logistic European System for Cardiac Operative Risk Evaluation (euroSCORE) (http://www.euroscore.org/) and Society of Thoracic Surgeons (STS) score (http://riskcalc.sts.org/STSWebRiskCalc273/), as well as adjunctive risk evaluation, such as the presence of advanced liver cirrhosis and severe neurologic impairment. Frailty and biological status were evaluated by the institutional Heart Team after collegial discussion, according to the so-called eyeball test. Quality of life of all the patients was evaluated by the Minnesota Living with Heart Failure Questionnaire (MLHFQ) and the 36-Item Short-Form Health Survey (SF-36); the 6-minute walk test (6MWT) was used to evaluate functional capacity.

\section{Follow-up}

All patients were followed up after discharge in a dedicated outpatient clinic with physical examination, electrocardiogram, transthoracic echocardiogram, and arrhythmology consultation whenever indicated. Follow-up visits were performed at 1 month, 6 months, and then yearly.

\section{Statistical Analysis}

Statistical analysis was conducted using JMP 11.0 software (SAS Institute Inc, Cary, NC). Continuous variables are presented as mean \pm standard deviation or as median (interquartile range [IQR], Q1-Q3), and categoric variables are expressed as percentages. Univariable comparisons were performed with Student unpaired or paired $t$ test for continuous normally distributed data, which were tested by the Shapiro-Wilk normality test. The Mann-Whitney rank-sum test was used for comparisons of nonparametric continuous data, and the chi-square test was used for categoric data. Survival and freedom from $3+$ or greater MR were presented using the Kaplan-Meier method; comparisons were performed with the logrank test. All reported $P$ values are 2-sided.

\section{RESULTS \\ Patient Characteristics}

The study population consisted of 48 high-risk consecutive patients with severe or moderate to severe DMR who underwent MitraClip implantation between October 2008 and July 2013 in San Raffaele University Hospital, Milan. During the same period, 2370 patients underwent surgical mitral repair (with or without associated procedure), and 116 patients underwent MitraClip implantation for functional MR.

The mean age of the study population was $78.5 \pm 10.8$ years; $56.6 \%$ of the patients were aged 80 years or more. The mean logistic euroSCORE at baseline was $15.7 \pm 11.2$; the mean STS score was $12 \% \pm 10 \%$ (range, $2 \%-36 \%$; IQR, $4-18$ ); $40 \%$ and $45.5 \%$ of patients had a baseline logistic euroSCORE $20 \%$ or greater and STS score $10 \%$ or greater, respectively. Patients presented multiple comorbidities. The baseline characteristics of all the patients are summarized in Table 1 (including data from ACCESSEUROPE (ACCESS-EU) phase I DMR cohort for comparison). ${ }^{13}$ Stratification into patients aged less than 80 years and patients aged 80 years or more revealed important demographic differences (mean logistic euroSCORE 
TABLE 1. Baseline demographics and comorbidities

\begin{tabular}{|c|c|c|c|c|c|}
\hline Characteristic & Overall $(n=48)$ & Age $<80$ y $(n=21)$ & Age $\geq 80$ y $(n=27)$ & $P$ value & $\begin{array}{l}\text { ACCESS-EU DMR } \\
(\mathbf{n}=117)\end{array}$ \\
\hline Age (y) & $78.5 \pm 10.8$ & $70.2 \pm 11$ & $84.8 \pm 3$ & $<.0001$ & $75.6 \pm 12.1$ \\
\hline Female (n, \%) & $22(46)$ & $9(42)$ & $13(48)$ & .7 & $59(50.4)$ \\
\hline Logistic euroSCORE $(\%)$ & $15.7 \pm 12.2$ & $12.1 \pm 8.5$ & $18.5 \pm 12$ & .04 & $15.5 \pm 13.3$ \\
\hline STS-PROM $(\%)$ & $12 \pm 10$ & $8.3 \pm 6$ & $15.1 \pm 11$ & .02 & na \\
\hline Previous cardiac surgery $(\mathrm{n}, \%)$ & $10(21)$ & $6(28)$ & $4(14)$ & .2 & $28(23.9)$ \\
\hline Previous percutaneous intervention $(\mathrm{n}, \%)$ & $7(14.5)$ & $3(14)$ & $4(14)$ & .9 & $32(27.6)$ \\
\hline $\mathrm{CAD}(\mathrm{n}, \%)$ & $19(39.5)$ & $9(42)$ & $10(37)$ & .7 & $48(41)$ \\
\hline $\mathrm{AF}(\mathrm{n}, \%)$ & $25(52)$ & $7(33)$ & $18(66)$ & .02 & $67(58.8)$ \\
\hline Baseline serum creatinine $(\mathrm{mg} / \mathrm{dL})$ & $1.1 \pm 0.4$ & $0.9 \pm 0.2$ & $1.3 \pm 0.3$ & .006 & na \\
\hline COPD $(\%)$ & $14(29)$ & $6(28)$ & $8(29)$ & .3 & $17(14.7)$ \\
\hline Cerebrovascular disease (n, \%) & $5(10.5)$ & $1(4)$ & $4(14)$ & .2 & $12(10.3)$ \\
\hline Extracardiac arteriopathy $(\mathrm{n}, \%)$ & $6(12.5)$ & $2(9)$ & $4(14)$ & .6 & na \\
\hline Diabetes $(\mathrm{n}, \%)$ & $4(8.3)$ & $3(6)$ & $1(4)$ & .4 & $17(14.5)$ \\
\hline NYHA class III-IV (n, \%) & $34(70.8)$ & $14(66)$ & $20(74)$ & .5 & $113(96.4)$ \\
\hline Previous ICD-CRT (n, \%) & $1(2)$ & 0 & $1(3.7)$ & .3 & $2(1.7)$ \\
\hline
\end{tabular}

Bold indicates $P<.05$. ACCESS-EU, ACCESS-EUROPE; $A F$, atrial fibrillation; $C A D$, coronary artery disease; $C O P D$, chronic obstructive pulmonary disease; $D M R$, degenerative mitral regurgitation; euroSCORE, European System for Cardiac Operative Risk Evaluation; ICD-CRT, Implantable Cardioverter Defibrillator-Cardiac Resynchronization Therapy; na, not available; NYHA, New York Heart Association; STS-PROM, Society of Thoracic Surgeons Predicted Risk of Mortality.

$12.1 \% \pm 8.5 \%$ and $18.5 \% \pm 12 \%$, respectively, $P=.04$ ). The majority of the patients had severe symptoms of heart failure at baseline, with $60.5 \%$ in New York Heart Association (NYHA) functional class III and $10.5 \%$ in class IV.

Quality of life questionnaire revealed an important impairment in perceived quality of life in all patients (MLHFQ was $35.4 \pm 12$; SF-36 physical domain was $38.6 \pm 7.9$; SF-36 mental domain was $42.5 \pm 8.7$ ). A tendency toward worst perceived quality of life was observed in patients aged 80 years or more (MLHFQ $33 \pm 14$ vs $36 \pm 8 ; P=.3$; SF-36 physical domain $40.6 \pm 6$ vs $42.4 \pm 8 ; P=.06$; SF-36 mental domain $42.7 \pm 9$ vs $42.4 \pm 8 ; P=.4$ ). Patients aged more than 80 years had the worst performance on the 6MWT (262.3 \pm 110.4 minutes vs $180.1 \pm 64.7$ minutes; $P=.004)$.

Preoperative median pro-brain natriuretic peptide value was $1026 \mathrm{pg} / \mathrm{mL}$ (IQR, 346-1895 pg/mL), without any difference according to age. Table 2 shows in detail the preoperative echocardiography of the study population. All patients had an MR grade of $3+$ of $4+$ at baseline; the mean left ventricular ejection fraction was $57 \% \pm 11 \%$.

\section{Procedural and In-Hospital Outcomes}

The device was successfully implanted in 47 of 48 patients $(98 \%)$; 1 patient was converted to conventional surgical MV replacement because of clip entanglement in the subvalvular apparatus in the commissural region, with the impossibility to retrieve the device.

One clip was implanted in 16 patients (33.3\%), 2 clips were implanted in 29 patients $(60.4 \%)$, and 3 clips were implanted in 2 patients $(4.1 \%)$. The median procedural time (defined as the time from start of the transseptal procedure until the removal of the Steerable Guide Catheter) was 94 minutes (IQR, 69-130 minutes; 6 minutes less compared with ACCESS-EU DMR). ${ }^{13}$

Safety outcomes at 30 days are shown in Table 3; 30-day mortality was $2 \%$ (1/48 patients died of septic shock and multiorgan failure after conversion to open mitral surgery). There was no incidence of acute myocardial infarction, stroke, major vascular complication, or cardiac tamponade at 30 days. Blood transfusion was required in 2 patients $(4 \%)$; severe acute renal failure occurred in 1 patient

TABLE 2. Preoperative echocardiography

\begin{tabular}{|c|c|c|c|c|c|}
\hline Characteristic & Overall $(n=48)$ & Age $<80$ y $(n=21)$ & Age $\geq 80$ y $(n=27)$ & $P$ value & ACCESS-EU DMR $(n=117)$ \\
\hline LVEF (\%) & $57.9 \pm 11$ & $55.3 \pm 13$ & $59.9 \pm 8$ & .1 & na \\
\hline LVEF $<40 \%(n, \%)$ & $6(12.5)$ & $4(19)$ & $2(7.4)$ & .2 & $11(9.4)$ \\
\hline $\operatorname{LVEDD}(\mathrm{mm})$ & $56.9 \pm 8$ & $60.4 \pm 9$ & $54.4 \pm 6$ & .01 & na \\
\hline LVESD (mm) & $35.3 \pm 7$ & $37 \pm 8.7$ & $34 \pm 6.7$ & .2 & $35 \pm 9$ \\
\hline sPAP (mm Hg) & $46.4 \pm 14$ & $42.1 \pm 13$ & $49.7 \pm 14.8$ & .03 & na \\
\hline TR 3-4+ (n, \%) & $9(19.5)$ & $2(10)$ & $7(27)$ & .1 & na \\
\hline Central lesion (n, \%) & $44(92)$ & $19(90)$ & $25(93)$ & .3 & na \\
\hline Flail width $(\mathrm{mm})$ & $12 \pm 2$ & $12.8 \pm 3$ & $12.4 \pm 2.3$ & .8 & na \\
\hline Flail gap (mm) & $4.6 \pm 1.4$ & $5.5 \pm 1.6$ & $4.1 \pm 1$ & .04 & na \\
\hline
\end{tabular}

Bold indicates $P<.05$. ACCESS-EU, ACCESS-EUROPE; $D M R$, degenerative mitral regurgitation; $L V E D D$, left ventricle end-diastolic diameter; $L V E F$, left ventricular ejection fraction; $L V E S D$, left ventricle end-systolic diameter; $n a$, not available; $S P A P$, systolic pulmonary artery pressure; $T R$, tricuspid regurgitation. 
TABLE 3. Thirty-day safety outcomes

\begin{tabular}{|c|c|c|c|c|c|}
\hline 30-d outcome & Overall $(n=48)$ & Age $<80$ y $(n=21)$ & Age $\geq 80$ y $(n=27)$ & $P$ value & ACCESS-EU DMR $(n=117)$ \\
\hline Death $(n, \%)$ & $1(2)$ & 0 & $1(3)$ & .3 & $7(6)$ \\
\hline Conversion to surgery $(\mathrm{n}, \%)$ & $1(2)$ & 0 & $1(3)$ & .3 & $2(1.7)$ \\
\hline Stroke $(\mathrm{n}, \%)$ & 0 & 0 & 0 & - & $1(0.9)$ \\
\hline $\operatorname{AMI}(n, \%)$ & 0 & 0 & 0 & - & $1(0.9)$ \\
\hline Renal failure (n, \%) & $1(2)$ & 0 & $1(3)$ & .3 & $3(2.6)$ \\
\hline Bleeding complications (n, \%) & $2(4)$ & 0 & $2(8)$ & .2 & $4(3.4)$ \\
\hline Cardiac tamponade (n, \%) & 0 & 0 & 0 & - & $1(0.9)$ \\
\hline ICU stay $<24 \mathrm{~h}(\mathrm{n}, \%)$ & $36(75)$ & $18(81)$ & $18(70)$ & & na \\
\hline
\end{tabular}

ACCESS-EU, ACCESS-EUROPE; AMI, acute myocardial infarction; $D M R$, degenerative mitral regurgitation; $I C U$, intensive care unit; $n a$, not available.

$(2 \%)$. The median stay in the intensive care unit was 22 hours (IQR, 18-24 hours); the stay in the intensive care unit was less than 1 day in $75 \%$ of patients (36/48). Patients were discharged from the hospital in an average of $4.5 \pm 2.4$ days ( $4.3 \pm 3$ days and $4.7 \pm 1.5$ days for patients aged $<80$ years and $\geq 80$ years, respectively; $P=.7$ ), with a median of 4 days after the MitraClip procedure. A minority of the patients were transferred to a cardiopulmonary rehabilitation facility ( 2 patients aged $<80$ years and 2 patients aged $\geq 80$ years; $P=.8$ ): $91.5 \%$ of hospital survivors (43/47 patients) were discharged directly home.

Predischarge echocardiography showed an MR reduction to grade $2+$ or less in 43 of 47 patients $(91.5 \%) ; 29$ of 47 patients $(61.7 \%)$ achieved an MR reduction to grade $1+$ or less. No differences in MR grade reduction were observed according to age group (Figure 1). No cases of mitral stenosis were observed: Postprocedural median MV area was $3 \mathrm{~cm}^{2}$ (IQR, 2.7-3.1 $\mathrm{cm}^{2}$ ), and predischarge systolic pulmonary artery pressure was $37.8 \pm 10 \mathrm{~mm} \mathrm{Hg}$ $(P=.03$ compared with baseline $)$.

\section{Follow-up}

The median follow-up was 16 months (IQR, 2-23 months). Overall actuarial survival was $89 \% \pm 5.2 \%$ and

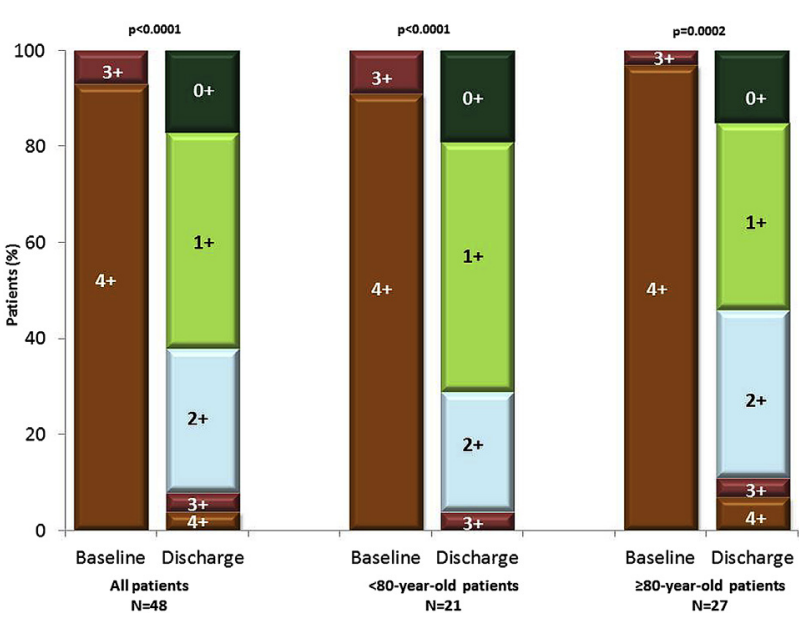

FIGURE 1. MR at baseline and at discharge echocardiography.
$70.2 \% \pm 9 \%$ at 1 and 2 years, respectively, for the entire study population; no differences were observed between patients aged less than 80 years and patients aged 80 years or more $(82 \% \pm 9 \%$ and $95 \% \pm 4.4 \%$ at 1 year, respectively; $P=.9$ ) (Figure 2). Causes of death were classified as cardiac in $33 \%$ of the cases. After discharge, 1 patient $(2 \%)$ underwent mitral surgery 2 years after the procedure; 1 patient $(2 \%)$ repeated the MitraClip procedure 1 month after the index procedure.

Actuarial freedom from MR 3+ or greater was $80 \% \pm$ $7 \%$ at 1 year and $76.6 \% \pm 7 \%$ at 2 years (Figure 3). There were no statistically significant differences in patients aged less than 80 years compared with patients aged 80 years or more $(86.5 \% \pm 8 \%$ and $75 \% \pm 9 \%$, respectively; $P=.5)$. At 1 year, $93 \%$ of survivors were in NYHA class I or II $(100 \%$ of patients aged $<80$ years and $88 \%$ of patients aged $\geq 80$ years; $P=.4$ ) (Figure 4 ).

A significant improvement was documented with all the quality of life assessments: MLHFQ was $18.1 \pm 10$, SF-36 physical domain was $44.3 \pm 7$, and SF-36 mental domain was $49 \pm 8.3(P<.0001, P=.005$, and $P=.01$, respectively, compared with preoperative values). A significant improvement in 6MWT performance was observed (262 \pm 91 minutes; mean improvement, 48 minutes;

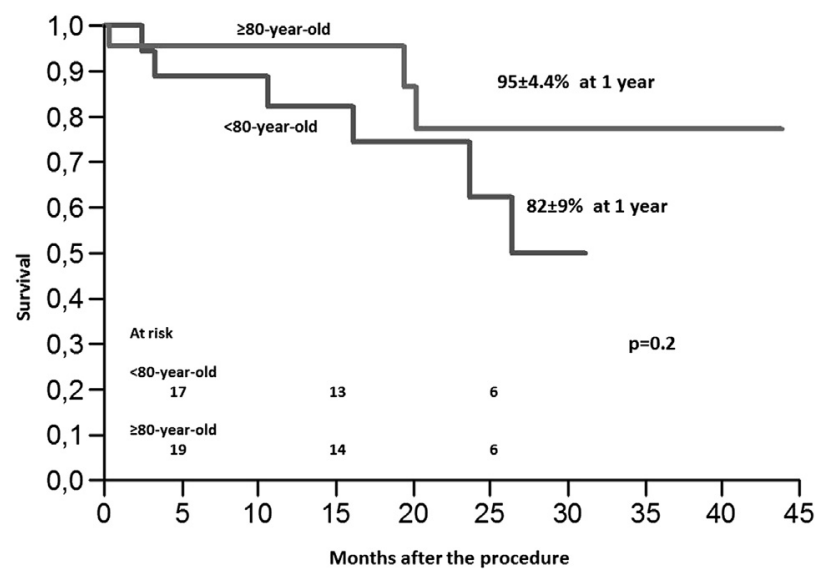

FIGURE 2. Actuarial survival at follow-up in patients aged less than 80 years and patients aged 80 years or more. 


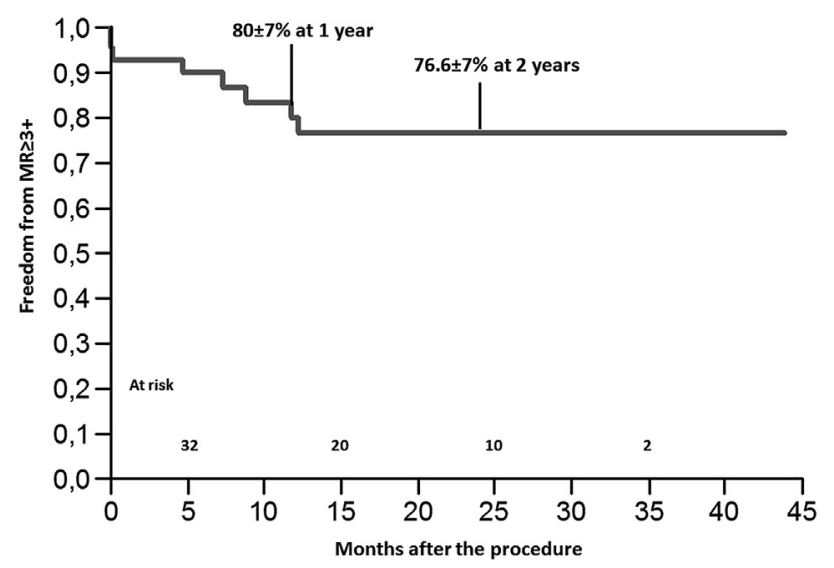

FIGURE 3. Actuarial freedom from MR $3+$ or greater at follow-up. $M R$, Mitral regurgitation.

$P=.005)$. Significant improvements in perceived quality of life and performance of 6MWT were observed in both patients group (Figure 5, $A$ and $B$ ).

\section{DISCUSSION}

Surgical MV repair is the treatment of choice for patients with severe DMR. ${ }^{20,21}$ Therefore, modern MV surgery is the benchmark for any new technique today, including MitraClip therapy. However, MR is a frequent condition in elderly persons (especially degenerative cause). ${ }^{9,22}$ Advanced age is one of the main risk factors of mortality and morbidity after cardiac surgery $(\sim 78 \%$ of the major complications after cardiac surgery and deaths occurred in elderly patients). ${ }^{23}$ Although favorable outcomes are reported even in elderly patients after isolated mitral repair, ${ }^{3}$ operative mortality and morbidity are high in elderly patients in the presence of co-pathologies and associated surgical procedures. ${ }^{22}$

Badhwar and colleagues ${ }^{24}$ recently reported the outcomes after MV repair in 14,604 patients aged more than

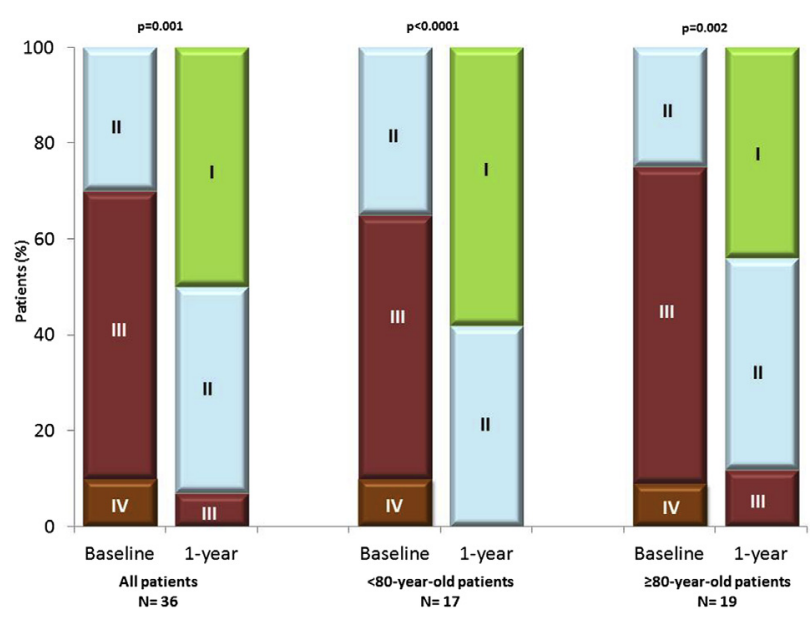

FIGURE 4. NYHA functional class at baseline and 1 year.
65 years. In patients aged more than 80 years with advanced heart failure symptoms (NYHA class III-IV), operative mortality was 5.3\% and 5-year survival was $68 \%$. The 5-year rates of recurrence of heart failure, major bleeding, and stroke were $28.8 \%, 12.3 \%$, and $11.7 \%$, respectively.

Seeburger and colleagues ${ }^{25}$ reported the single-center experience with 2053 elderly (aged $\geq 70$ years) patients who underwent MV surgical procedures with or without associated procedures. Seventy-seven patients $(3.1 \%)$ died within 30 days after the operation. Cerebrovascular accidents occurred in $4.2 \%$ of patients, and the incidence of acute renal failure was $16.7 \%$. Concomitant coronary artery bypass grafting was a significant risk factor for increased early mortality. Five-year survival for patients aged more than 80 years was $47.9 \%$, and associated comorbidities were associated with an increased risk of late death.

Chikwe and colleagues ${ }^{26}$ reported the results of a consecutive series of 322 octogenarians operated over a period of 10 years. Approximately half of the patients underwent MV surgery combined with coronary artery bypass grafting. The surgical risk was apparently acceptable only in patients treated with an isolated elective repair, with a mortality of approximately $5 \%$ at 30 days. However, mortality at 3 months was approximately $13 \%$, indicating that octogenarians are not likely to recover easily from the trauma of open surgery.

Currently, up to $50 \%$ of the patients with severe MR are not referred for surgery because of high predicted surgical risk or advanced age. ${ }^{8}$ According to the European Society of Cardiology 2012 Guidelines, ${ }^{7}$ percutaneous edge-toedge procedure may be considered in patients with symptomatic severe DMR who fulfill the echocardiographic criteria of eligibility, are judged inoperable or at high surgical risk by a heart team, and have a life expectancy greater than 1 year (class IIb, level of evidence C).

Data from the Endovascular Valve Edge-to-Edge Repair of Mitral Regurgitation Study (EVEREST) trials and from registries in Europe and the United States showed that the MitraClip procedure has a procedural success rate (postprocedural $\mathrm{MR} \leq 2+$ ) of approximately $75 \%$ and is relatively safe and generally well tolerated, even by patients in poor clinical condition. ${ }^{10-18}$ Patients currently treated in the real world with MitraClip therapy for DMR are different from those enrolled in the EVEREST II randomized trial, which included surgical low-risk candidates. The High Risk Registry Study, an arm of the EVEREST II trial, enrolled symptomatic patients with moderate to severe or severe MR for whom surgical risk for perioperative mortality rate was estimated to be greater than $12 \%$ with STS score. In this series, $88.5 \%$ of the patients had 5 or more associated co-pathologies and $83 \%$ of the patients were aged more than 75 years. ${ }^{17} \mathrm{~A}$ degenerative cause was present in 62 patients. At 30 days, 4 of 62 patients $(6.5 \%)$ with DMR who were treated with MitraClip died. 


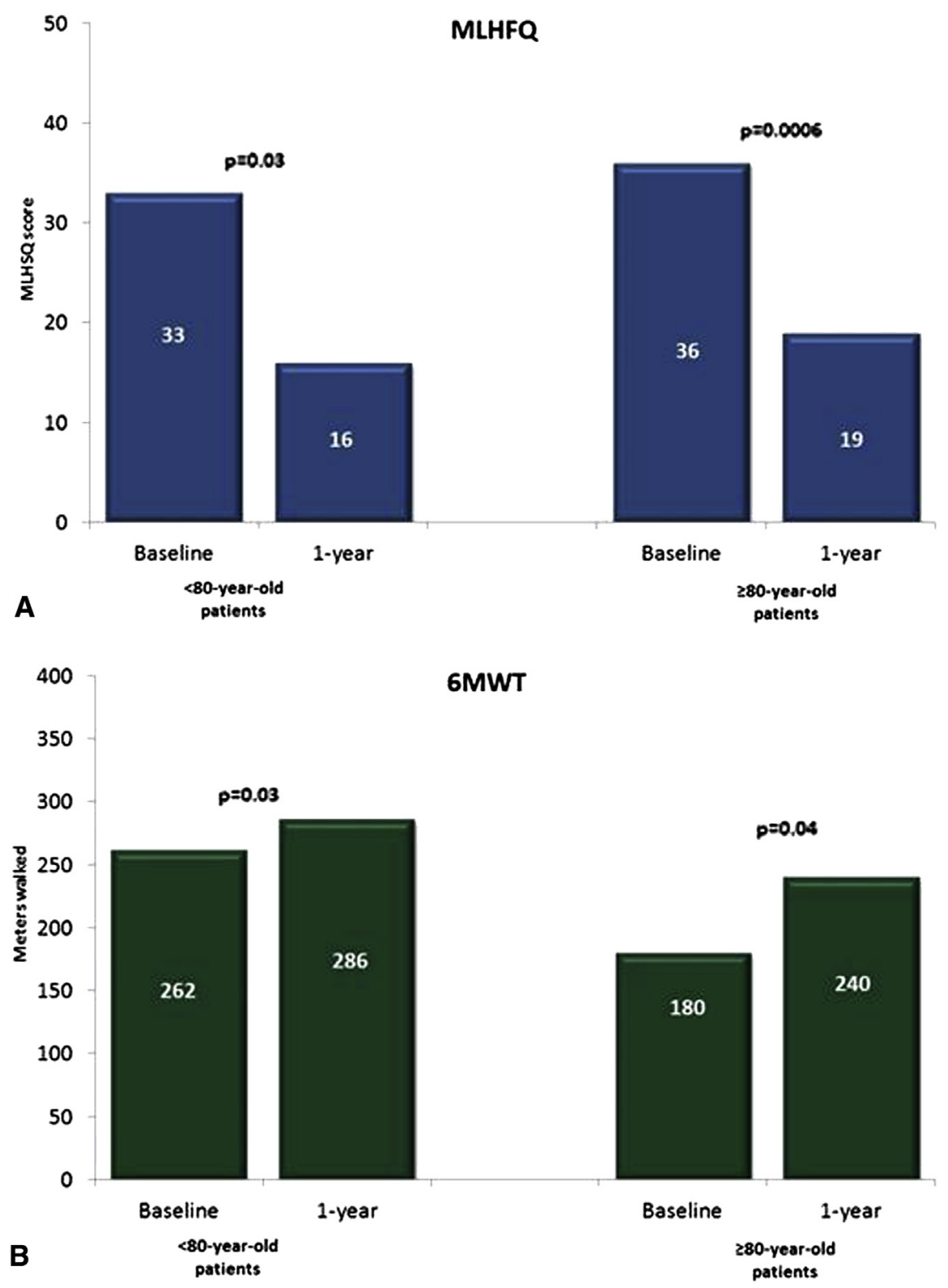

FIGURE 5. A, Results of MLHFQ in patients aged less than 80 years and patients aged 80 years or more. B, Results of $6 \mathrm{MWT}$ in patients aged less than 80 years and patients aged 80 years or more. MLHFQ, Minnesota Living with Heart Failure Questionnaire; 6MWT, 6-minute walk test.

The results of the DMR cohort of the ACCESS-EU Phase I study showed satisfactory clinical outcomes in selected high-risk patients ${ }^{13}$ : A total of 117 patients (mean age, $75.6 \pm 12$ years; mean logistic euroSCORE, $15.5 \% \pm$ $13.3 \%$ ) with DMR underwent the MitraClip procedure. However, a 30-day mortality of $6.0 \%$ was reported. In a subgroup of patients with particularly high risk (mean logistic euroSCORE $33 \% \pm 11 \%$ ), observed mortality was $9.1 \%$. Likewise, Lim and colleagues ${ }^{18}$ reported a $6.3 \%$ 30-day mortality in 141 high-risk patients with DMR (mean age, 82 years).

The major finding of the present study concerns the high level of safety of MitraClip therapy in high-risk and elderly patients with DMR if appropriate patient selection is performed. In our experience, 30-day mortality was remarkably low $(2 \%$ overall; $3 \%$ in patients aged $>80$ years). Although patients treated in San Raffaele University Hospital experience were older compared with those in the ACCESS-EU DMR, they had a similar baseline risk profile (logistic euroSCORE, $15.7 \pm 12.2$ ). The relatively higher 30-day mortality reported in the registries may reflect the fact that they are real-world registries, in which many procedures, at least at the beginning of the enrollment, were performed in very sick patients as compassionate and probably futile treatment. The low mortality and extremely low morbidity reported in our experience show the importance of careful patient selection to identify those who could benefit from the procedure and to reduce procedural risk. 
It is important to point out that patient selection is fundamental to obtain successful procedural results. In our experience, we observed a procedural success of $98 \%$, which is satisfactory, especially in degenerative cause, and favorably compares with other large real-world MitraClip series of patients with DMR $\left(94 \%\right.$ in ACCESS-EU DMR, ${ }^{13}$ $\sim 80 \%$ reported by Rudolph and colleagues ${ }^{14}$ in patients with DMR).

At follow-up, we observed an actuarial survival of $89 \%$ $\pm 5.2 \%$ and $70.2 \% \pm 9 \%$ at 1 and 2 years, respectively, without differences between patients aged less than 80 years and patients aged 80 years or more, which favorably compares with other MitraClip series (1-year mortality ranging from $6 \%$ to $24 \%$ ) and with the previously mentioned surgical reports. ${ }^{15-18}$

In regard to echocardiographic outcome, our experience showed an acute reduction of MR to grade $2+$ or less in $91.5 \%$, and in $61.7 \%$ an MR reduction to grade 1 or less was achieved. These results are consistent with those reported in the ACCESS DMR registry (reduction of MR to grade $\leq 2+$ in $88.7 \%$ ) and favorably compared with the EVEREST II trial $(77 \%){ }^{10,13}$ Freedom from MR $3+$ or greater was $80 \% \pm 7 \%$ and $76.6 \% \pm 7 \%$ at 1 and 2 years, respectively. If compared with reparative mitral surgery, these results are inferior, confirming that surgery is so far the gold standard therapy for DMR. However, it should be considered that the patients included in the present study, like the majority of the patients currently treated with MitraClip, are high-risk surgical candidates or inoperable patients. Although estimated surgical risk was high, meaningful clinical improvements were documented. In fact, except for intraoperative and early postoperative risks, it would seem equally or even more important, especially in elderly patients, integrated evaluation of the quality of life and functional status, to judge whether a certain procedure could lead to the expected functional improvement. In a retrospective study including 225 patients aged more than 70 years who underwent mitral surgery for severe DMR, Maisano and colleagues ${ }^{27}$ demonstrated that quality of life after surgery is suboptimal in more than half of the patients, even if the patient survives after the operation.

Important clinical benefits were documented at 1 year even in patients aged more than 80 years, in terms of NYHA class, quality of life, and functional status tested by walk test improvements. In our experience, MLHFQ scores, SF-36 scores, and 6MWT performance improved significantly at 12 months compared with baseline ( $P=.03$ and $P<.0001$, respectively). Significant improvements were observed in patients aged more than 80 years. This is consistent with the ACCESS-EU DMR results at 1 year and with other reports in different clinical settings. ${ }^{10,12,17,28}$

\section{Study Limitations}

This study was an observational, retrospective, singlecenter study; therefore, the sample size is too small to make strong conclusions. Moreover, the results include an initial learning curve.

\section{CONCLUSIONS}

The results of this single-center experience confirm that MitraClip therapy is a valuable alternative to surgery in high-risk and elderly patients with DMR. Clinical benefits are evident at 1 year and also obtained in octogenarians. Although patients treated in current practice are high risk, the procedure remains safe and effective in selected patients. Durability of MR reduction and clinical benefit warrant further monitoring of patients after MitraClip implantation during long-term follow-up.

\section{References}

1. Yun KL, Miller DC. Mitral valve repair versus replacement. Cardiol Clin. 1991; 9:315-27.

2. Olson LJ, Subramanian R, Ackermann DM, Orszulak TA, Edwards WD. Surgical pathology of the mitral valve: a study of 712 cases spanning 21 years. Mayo Clin Proc. 1987;62:22-34.

3. Detaint D, Sundt TM, Nkomo VT, Scott CG, Tajik AJ, Schaff HV, et al. Surgical correction of mitral regurgitation in the elderly: outcomes and recent improvements. Circulation. 2006;114:265-72.

4. Gillinov AM, Blackstone EH, Nowicki ER, Slisatkorn W, Al-Dossari G, Johnston DR, et al. Valve repair versus valve replacement for degenerative mitra valve disease. J Thorac Cardiovasc Surg. 2008;135:885-93.

5. Adams DH, Anyanwu AC, Rahmanian PB, Abascal V, Salzberg SP, Filsoufi F. Large annuloplasty rings facilitate mitral valve repair in Barlow's disease. Ann Thorac Surg. 2006;82:2096-100.

6. Flameng W, Herijgers P, Bogaerts K. Recurrence of mitral valve regurgitation after mitral valve repair in degenerative valve disease. Circulation. 2003;107: 1609-13.

7. Vahanian A, Alfieri O, Andreotti F, Antunes MJ, Barón-Esquivias G, Baumgartner H, et al. Guidelines on the management of valvular heart disease (version 2012). Eur Heart J. 2012;33:2451-96.

8. Mirabel M, Iung B, Baron G, Messika-Zeitoun D, Détaint D, Vanoverschelde JL, et al. What are the characteristics of patients with severe, symptomatic, mitral regurgitation who are denied surgery? Eur Heart J. 2007; 28:1358-65.

9. Nkomo VT, Gardin JM, Skelton TN, Gottdiener JS, Scott CG, Enriquez Sarano M. Burden of valvular heart diseases: a population-based study. Lancet 2006;368:1005-11

10. O'Brien SM, Shahian DM, Filardo G, Ferraris VA, Haan CK, Rich JB, et al. The Society of Thoracic Surgeons 2008 cardiac surgery risk models: part 2-isolated valve surgery. Ann Thorac Surg. 2009;88:S23-42.

11. Feldman T, Foster E, Glower DD, Kar S, Rinaldi MJ, Fail PS, et al. Percutaneous repair or surgery for mitral regurgitation. N Engl J Med. 2011;364:1395-406.

12. Writing Committee Members, O'Gara PT, Calhoon JH, Moon MR, Tommaso CL. Transcatheter therapies for mitral regurgitation: a professional society overview from the American College of Cardiology, The American Association for Thoracic Surgery, Society for Cardiovascular Angiography and Interventions Foundation, and The Society of Thoracic Surgeons. J Thorac Cardiovasc Surg. 2014;147:837-49.

13. Reichenspurner H, Schillinger W, Baldus S, Hausleiter J, Butter C, Schäefer U, et al. Clinical outcomes through 12 months in patients with degenerative mitral regurgitation treated with the MitraClip(R) device in the ACCESS-EUrope Phase I trial. Eur J Cardiothorac Surg. 2013;44:e280-8.

14. Rudolph V, Knap M, Franzen O, Schlüter M, de Vries T, Conradi L, et al. Echocardiographic and clinical outcomes of MitraClip therapy in patients not amenable to surgery. J Am Coll Cardiol. 2011;58:2190-5.

15. Schillinger W, Hünlich M, Baldus S, Ouarrak T, Boekstegers P, Hink U, et al Acute outcomes after MitraClip therapy in highly aged patients: results from 
the German TRAnscatheter Mitral valve Interventions (TRAMI) Registry. Eurointervention. 2013;9:84-90.

16. Maisano F, Franzen O, Baldus S, Schäfer U, Hausleiter J, Butter C, et al. Percutaneous mitral valve interventions in the real world: early and one year results from the ACCESS-EU, a prospective, multicenter, non-randomized postapproval study of the MitraClip ${ }^{\circledR}$ therapy in Europe. J Am Coll Cardiol. 2013; 62:1052-61.

17. Whitlow PL, Feldman T, Pedersen WR, Lim DS, Kipperman R, Smalling R, et al Acute and 12-month results with catheter-based mitral valve leaflet repair: the EVEREST II (Endovascular Valve Edge-to-Edge Repair) High Risk Study. J Am Coll Cardiol. 2012;59:130-9.

18. Lim DS, Reynolds MR, Feldman T, Kar S, Herrmann HC, Wang A, et al. Improved functional status and quality of life in prohibitive surgical risk patients with degenerative mitral regurgitation following transcatheter mitral valve repair with the MitraClip ${ }^{\circledR}$ system. J Am Coll Cardiol. 2013 Oct 24 [Epub ahead of print].

19. Maisano F, Denti P, Michev I, La Canna G, Arendar I, Colombo A, et al. Percutaneous mitral valve repair with the edge-to-edge technique. Multimed Man Cardiothorac Surg. 2010 Jan 1;2010. mmets.2009.004002.

20. Gammie JS, O'Brien SM, Griffith BP, Ferguson TB, Peterson ED. Influence of hospital procedural volume on care process and mortality for patients undergoing elective surgery for mitral regurgitation. Circulation. 2007;115:881-7.

21. Savage EB, Ferguson TB Jr, DiSesa VJ. Use of mitral valve repair: analysis of contemporary United States experience reported to the Society of
Thoracic Surgeons National Cardiac Database. Ann Thorac Surg. 2003;75 $820-5$.

22. Iung B, Baron G, Butchart EG, Delahaye F, Gohlke-Bärwolf C, Levang OW, et al A prospective survey of patients with valvular heart disease in Europe: The Euro Heart Survey on Valvular Heart Disease. Eur Heart J. 2003;24:1231-43.

23. Mehta RH, Eagle KA, Coombs LP, Peterson ED, Edwards FH, Pagani FD, et al Influence of age on outcomes in patients undergoing mitral valve replacement. Ann Thorac Surg. 2002;74:1459-67.

24. Badhwar V, Peterson ED, Jacobs JP, He X, Brennan JM, O’Brien SM, et al. Longitudinal outcome of isolated mitral repair in older patients: results from 14,604 procedures performed from 1991 to 2007. Ann Thorac Surg. 2012;94:1870-7.

25. Seeburger J, Falk V, Garbade J, Noack T, Kiefer P, Vollroth M, et al. Mitral valve surgical procedures in the elderly. Ann Thorac Surg. 2012;94:1999-2003.

26. Chikwe J, Goldstone AB, Passage J, Anyanwu AC, Seeburger J, Castillo JG, et al A propensity score-adjusted retrospective comparison of early and mid-term results of mitral valve repair versus replacement in octogenarians. Eur Heart J 2011;32:618-26.

27. Maisano F, Viganò G, Calabrese C, Taramasso M, Denti P, Blasio A, et al. Quality of life of elderly patients following valve surgery for chronic organic mitra regurgitation. Eur J Cardiothorac Surg. 2009;36:261-6.

28. Treede H, Schirmer J, Rudolph V, Franzen O, Knap M, Schluter M, et al. A heart team's perspective on interventional mitral valve repair: percutaneous clip implantation as an important adjunct to a surgical mitral valve program for treatment of high-risk patients. J Thorac Cardiovasc Surg. 2012;143:78-84.

\section{EDITORIAL COMMENTARY}

\section{Percutaneous edge-to-edge repair for degenerative mitral regurgitation: A journey to the edge of the bell-shaped curve}

Patrick M. McCarthy, MD

See related article on pages 2743-50.

The report in this issue of the Journal by Taramasso and colleagues ${ }^{1}$ is a welcome addition, as most reports of MitraClip (Abbott Vascular, Santa Clara, Calif) outcomes have been in the cardiology literature. Taramasso and colleagues ${ }^{1}$ report excellent outcomes in a high-risk surgical population $(78.5 \pm 10.8$ years; $71 \%$ New York Heart

From the Cardiac Surgery Division, Bluhm Cardiovascular Institute, Northwestern University Feinberg School of Medicine, Chicago, Ill.

Disclosures: P.M.M. has a financial interest with Edwards Lifesciences (consultant, royalties, and intellectual property), where he is credited as inventor of the Edwards MC3 Ring and dETlogix Ring and coinventor of the IMR Etlogix Ring, and also serves as a consultant for Abbott Vascular.

Received for publication Oct 10, 2014; accepted for publication Oct 12, 2014.

Address for reprints: Patrick M. McCarthy, MD, Division of Cardiac Surgery, Northwestern University Feinberg School of Medicine, Northwestern University, 201 East Huron St, Suite 11-140, Chicago, IL 60611-2908 (E-mail: pmccart@nmh. org).

J Thorac Cardiovasc Surg 2014;148:2750-1

$0022-5223 / \$ 36.00$

Copyright $\Subset 2014$ Published by Elsevier Inc. on behalf of The American Association for Thoracic Surgery

http://dx.doi.org/10.1016/j.jtcvs.2014.10.071
Association functional class III or IV; mean Society of Thoracic Surgeons [STS] score $12 \% \pm 10 \%$ ) with severe degenerative mitral regurgitation (DMR). Their results mirror the US MitraClip experience presented to the Food and Drug Administration panel with a low procedural risk ( $2 \%$ in-hospital mortality), low morbidity, no clip embolization, a very high procedural "success" rate $(98 \%)$, and short stay relative to conventional surgery. ${ }^{2}$ DMR frequently is seen with an anatomically difficult lesion to treat with the MitraClip; however, there was a reasonable reduction in mitral regurgitation to grade II or less in $91.5 \%$ of patients. The 1-year survival $(89 \% \pm 5.2 \%)$, New York Heart Association functional class $(93 \%$ I or II), and 6-minute walk (mean improvement of 48 meters) were favorable. Initial trials in the United States included low- and medium-risk patients, the type of patients in the middle of the bell-shaped curve of patients treated with surgery, and reflected a strategy (and hubris) to compete directly with conventional heart surgery. These trials, principally the Endovascular Valve Edge-to-Edge Repair High Risk Study (EVEREST) and the continued access protocol, took a long time to execute as the tactics evolved and the target patient population shifted to the sickest patients on 